\title{
Heterobathmia pseuderiocrania Kristensen \& Nielsen (Lepidoptera, Heterobathmiidae): identificación basada en DNA-barcoding y notas morfológicas e historia de vida de los estados inmaduros
}

\author{
Rosa A. Ramos ${ }^{1,2} \&$ Luis E. Parra ${ }^{3}$
}

\author{
'Programa de Magíster en Ciencias Forestales, Facultad de Ciencias Forestales. Universidad de Concepción. Casilla 160-C. Concepción. Chile. \\ rosaramos@udec.cl \\ ${ }^{2}$ CONAF, Centro de Semillas, Genética y Entomología, Casilla 5, Chillán, Chile. rosa.ramos@conaf.cl \\ ${ }_{3}^{3}$ Departamento de Zoología. Facultad de Ciencias Naturales y Oceanográficas, Casilla 160-C, Concepción, Chile. luparra@udec.cl
}

\begin{abstract}
Heterobathmia pseuderiocrania Kristensen \& Nielsen (Lepidoptera, Heterobathmiidae): identification based on DNAbarcoding and notes on the morphology and life history of the immature stages. The larva morphology of the species Heterobathmia pseuderiocrania (Lepidoptera, Heterobathmiidae), a Nothofagus obliqua leafminer in Chile, is described. The tissue-feeding first and last instars are described. Also, the number of larval stages, some aspects of the biology and life cycle of the species are provided.
\end{abstract}

KEY WORDS. Biology; COI; egg; Insecta; morphology.

En el centro-sur de Chile abundan los bosques representados por el género Nothofagus, siendo Nothofagus obliqua (Mirb.) Oerst. una de las especies de mayor valor económico, social y ambiental para el país (Donoso 1994; Bauerle et al. 1997). A esta especie se encuentra asociado el minador de hoja Heterobathmia peseuderiocrania Kristensen \& Nielsen, 1979 (Lepidoptera, Heterobathmiidae). El género Heterobathmia Kristensen \& Nielsen 1979 (Heterobathmoidea, Heterobathmiidae) pertenece al grupo de las polillas NoGlossata. Heterobathmiidae es el grupo hermano de Glossata, por lo que acapara un excepcional interés filogenético (Kristensen \& Nielsen 1998). El clado No-Glossata está compuesto por: Micropterigidae + Agathiphagidae + Heterobathmiidae, y comprende lepidópteros desprovistos de espiritrompa o haustellum y otros rasgos apomórficos que caracterizan a Glossata (Kristensen 1999). Kristensen \& Nielsen (1998) señalan que Heterobathmia está presente en el bosque templado caducifolio de Nothofagus del sur de Chile y la Patagonia Argentina, entre los $39^{\circ}$ y $43^{\circ}$ latitud sur, y entre 600 y 1.400 metros de altitud (Kristensen \& Nielsen 1983). Hasta ahora, sólo cinco especies han sido descritas para el género, pero se reconocen diez. Las especies conocidas son Heterobathmia pseuderiocrania Kristensen \& Nielsen, 1979, H. diffusa Kristensen \& Nielsen, 1979 y H. valvifer Kristensen $\&$ Nielsen, 1998, y recientemente, se describieron dos nuevas especies: H. megadecella Hünefeld \& Kristensen, 2012 y $H$. nielsenella Hünefeld \& Kristensen, 2012 (Hünefeld \& Kristensen 2012). En Chile sólo se ha detectado la presencia de $H$. valvifer sobre Nothofagus pumilio en la Provincia de Osorno (Kristensen \& Nielsen 1998). Las larvas son minadoras de hojas y la temporada de vuelo de las mariposas adultas es a finales del invierno y principios de primavera (Kristensen \&
Nielsen 1983; Kristensen 1984; Nielsen 1985; Kristensen \& Nielsen 1998). H. pseuderiocrania es la especie más común del género, de acuerdo con las colectas hechas por sus autores en San Martín de Los Andes, Argentina (Kristensen \& Nielsen 1983). Kristensen \& Nielsen (1983) reportan al género Heterobathmia asociado a las siguientes especies de Nothofagus: N. procera (Poepp. \& Endl.) Oerst., N. obliqua (Mirb.) Oerst., N. antarctica (Forst) Oerst., y N. pumilio (Poepp. \& Endl.) Kras.

En el presente estudio se describe los instares larvales de H. peseuderiocrania, con especial énfasis en la estructura morfológica de los morfos que corresponden al instar temprano y tardío, y que se alimentan del tejido interno de la hoja (tissuefeeding).

\section{MATERIAL Y MÉTODOS}

Las muestras fueron colectadas en el Fundo Las Veguillas, localidad de Los Lleuques, comuna de Pinto, Región del Biobío ( $\left.36^{\circ} 52^{\prime} \mathrm{S}, 71^{\circ} 36^{\prime} \mathrm{W}\right)$. La metodología del estudio se basó en tres muestreos anuales consecutivos durante las temporadas 2009-2010, 2010-2011 y 2011-2012. Tanto huevos como larvas fueron colectados desde hojas con presencia de éstas a comienzos de primavera en el hemisferio sur.

La colecta de insectos se realizó mediante visitas semanales y quincenales durante el período en que estuvo presente el estado larval (primavera-verano), pupal (verano-otoño) y adulto (primavera-verano). Durante las tres temporadas de colecta sólo fue posible colectar el huevo y la larva para la especie, los que se encontraron dentro de las hojas minadas. Para la obtención de huevos y larvas neonatas fueron recolectadas hojas de árboles de roble que presentaban oviposturas recientes 
del minador. Paralelamente, se colectó hojarasca para la búsqueda de pupas del minador. La crianza de insectos fue realizada en el laboratorio de entomología del Centro de Semillas, Genética y Entomología, perteneciente a CONAF, ubicado en la ciudad de Chillán.

Para el estudio de caracteres morfológicos de la ultraestructura de larvas, éstas fueron fotografiadas bajo microscopio electrónico (SEM) en el Laboratorio de Microscopía Electrónica de la Universidad de Concepción. Para la identificación, las larvas de los últimos instares fueron destinadas a estudios moleculares para la secuenciación de ADN del gen mitocondrial Citocromo Oxidasa I (COI). El análisis molecular fue realizado en el laboratorio de Genética de Forestry and Agricultural Biotechnology Institute (FABI), de Sudáfrica. Se empleó el protocolo estándar para la amplificación de las regiones de interés mediante el método de PCR para la especie en estudio. Se utilizó la región conservada de las larvas COI para la secuenciación de los ejemplares. Se extrajo el ADN de las larvas, el que fue utilizado para la amplificación de la región que se encuentra localizada en el ADN mitocondrial y que contiene los pares de bases de la subunidad I del gen Citocromo Oxidasa (COI). Los ejemplares colectados fueron depositados en el Museo de Zoología de la Universidad de Concepción (UCCC-MZUC) y en el laboratorio de Entomología de CONAF, Chillán.

\section{RESULTADOS}

Identificación molecular del insecto. Los resultados del análisis molecular, después de comparar el COI de las larvas con secuencias publicadas para la especie, arrojan que el lepidóptero minador corresponde a la especie $H$. pseuderiocrania Kristensen \& Nielsen (Lepidoptera, Heterobathmidae) (datos no mostrados).

Descripción de los estados inmaduros. Huevo. El huevo es semi-esférico, presentando una parte convexa y la otra plana, forma que adquiere al encontrarse en la parte inferior de la hoja (Figs. 1-2), siendo rodeado de una secreción gelatinosa. Mide alrededor de $200 \mu \mathrm{m}$ de diámetro.

Material examinado. 3 huevos, Chile: Provincia de Nuble, Localidad de Los Lleuques, 853 m.s.n.m., 21 Oct 2011 (UCCC-MZUC).

Larva primer instar. (Figs. 3-11). Larva blanquecina a crema, comprimida dorso-ventralmente. Cabeza, comprimida dorso-ventralmente, proporcionalmente más grande que el cuerpo, muy esclerosada, castaña oscura, prognata, con sutura adfrontal en forma de "Y" en la cara dorsal del rostro. Quetotaxia reducida (Fig. 10), P2, F1, S2 y A3 presentes y dos pares de setas del labro. Stemmata detrás de la antena, con 5 pares de stemma, quinto stemma separado de los cuatro restantes, los que se disponen en forma contigua en una línea anterior lateral. Antenas muy cortas, tri-segmentadas y con un equipo sensorial que se ilustra en la Fig. 9. Aparato bucal, labro bilobulado, con 2 pares de setas en la superficie dorsal. Mandíbulas castaño oscuras, bastante esclerosadas, con 4 dientes; epifaringe con espínulas largas muy densas ubicadas
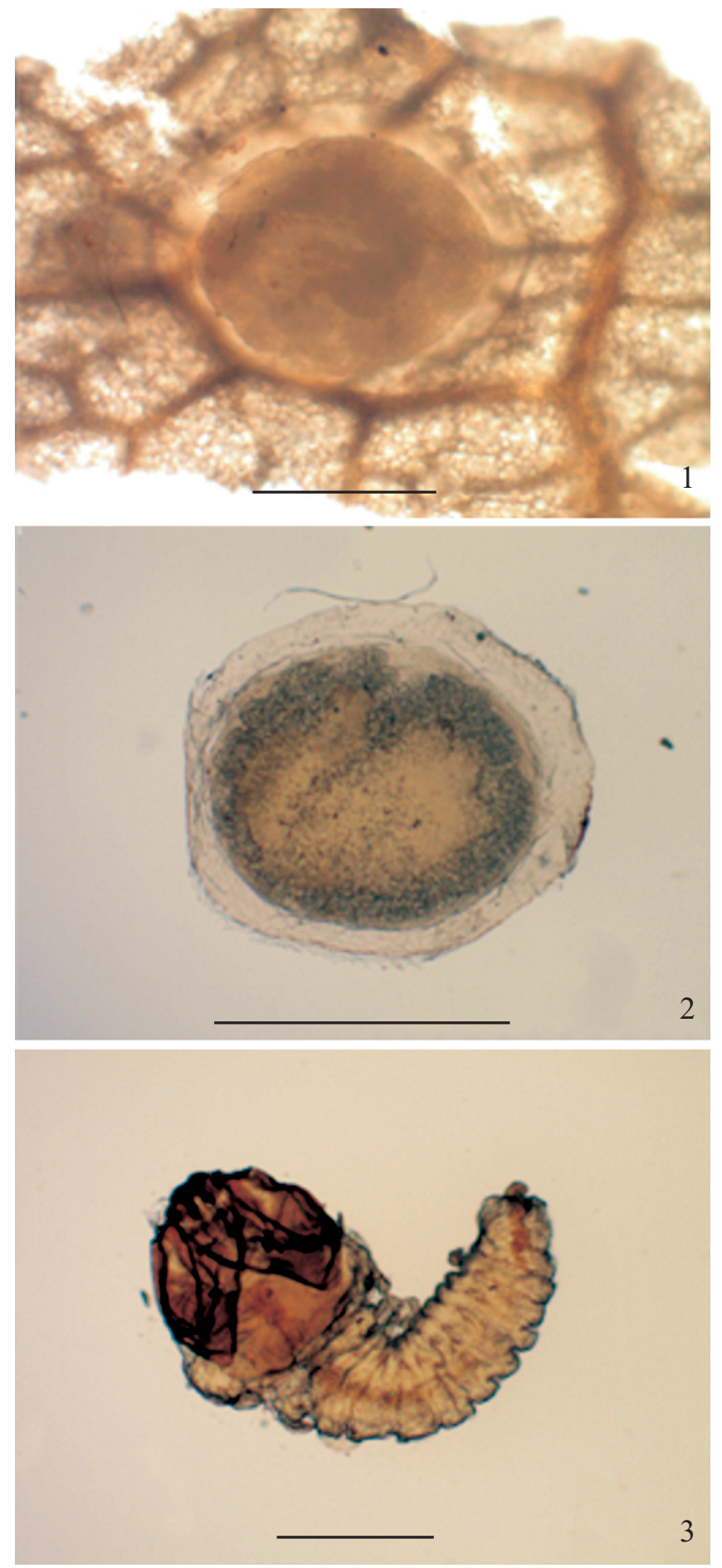

Figs. 1-3. H. pseuderiocrania. 1, Huevo sobre la cutícula abaxial de la hoja, escala $200 \mu \mathrm{m}$. 2, Huevo en desarrollo rodeado de sustancia gelatinosa que la hembra secreta al depositar el huevo, escala $200 \mu \mathrm{m}$. 3, Larva primer instar, escala $300 \mu \mathrm{m}$.

en el margen distal del labro; hipofaringe, maxilas poco desarrolladas y espinerete vestigial. Protórax prominente con un escudete torácico esclerosado, de menor tamaño en el meso y metatórax, patas poco desarrolladas. Abdomen, quetotaxia reducida, protórax D1, D2, SD1, SV1, SV2, L1 y L3 presen- 
tes, y un par de puncturas en la región media. En T2 y T3 con D1 y L1 presentes. Abdomen, segmentos A1-A9 con D1, L1 y SV1 presentes, A10 con SV2, SV3 y V1 presentes (Fig. 11). Callos dorsales presentes en T2-3 (Fig. 4) y en los segmentos abdominales A1-8 (Fig. 5).

Material examinado: Chile: 4 larvas, Provincia de Ñuble, Localidad de Los Lleuques, 853 m.s.n.m., Nov 2010 (UCCC-MZUC).

Larva último instar. (Figs.12-21). Larva blanquecina a crema, eruciforme. Cabeza hipognata, esclerosada, castaña oscura, con suturas en forma de "Y" en la cara dorsal del rostro; quetotaxia presente, P1 y P2, F1, A1, A2, A3, S2, C1, C2 presentes más dos pares de setas del labro (Fig. 20). Stemmata con 7 pares distribuidos en forma semicircular detrás de la antena. Antenas muy cortas, tri-segmentadas y con un equipo sensorial que se ilustra en la Fig. 18. Aparato bucal bien desarrollado, labro bilobulado, con 3 pares de setas en la superficie dorsal; mandíbulas castaño oscuras, bastante esclerosadas, con 4 dientes; hipofaringe, maxilas reducidas, espinerete simple, elongado. Protórax, placa torácica esclerosada, castaño oscura, XD1, XD2, D1, D2, SD1, SD2, L1, L2, L3, SV1, SV2 Y V1 presentes, T2 y T3 con D1, D2, SD1, SD2, L1, L2, SV2 y V1 presentes. Patas, prominentes y muy desarrolladas. Abdomen, quetotaxia presente, A1 y A2 con D1, D2, SD1, L1, L2, L3, SV1, SV2, V1 y V2 presentes, A3 con D1, D2, SD1, L1, L2, L3, SV1, SV2, SV3, V1 y V2 presentes, segmentos A4-A6 con D1, D2, SD1, L1, L2, L3, SV1, SV2, SV3 y V1 presentes, A7 con D1, D2,
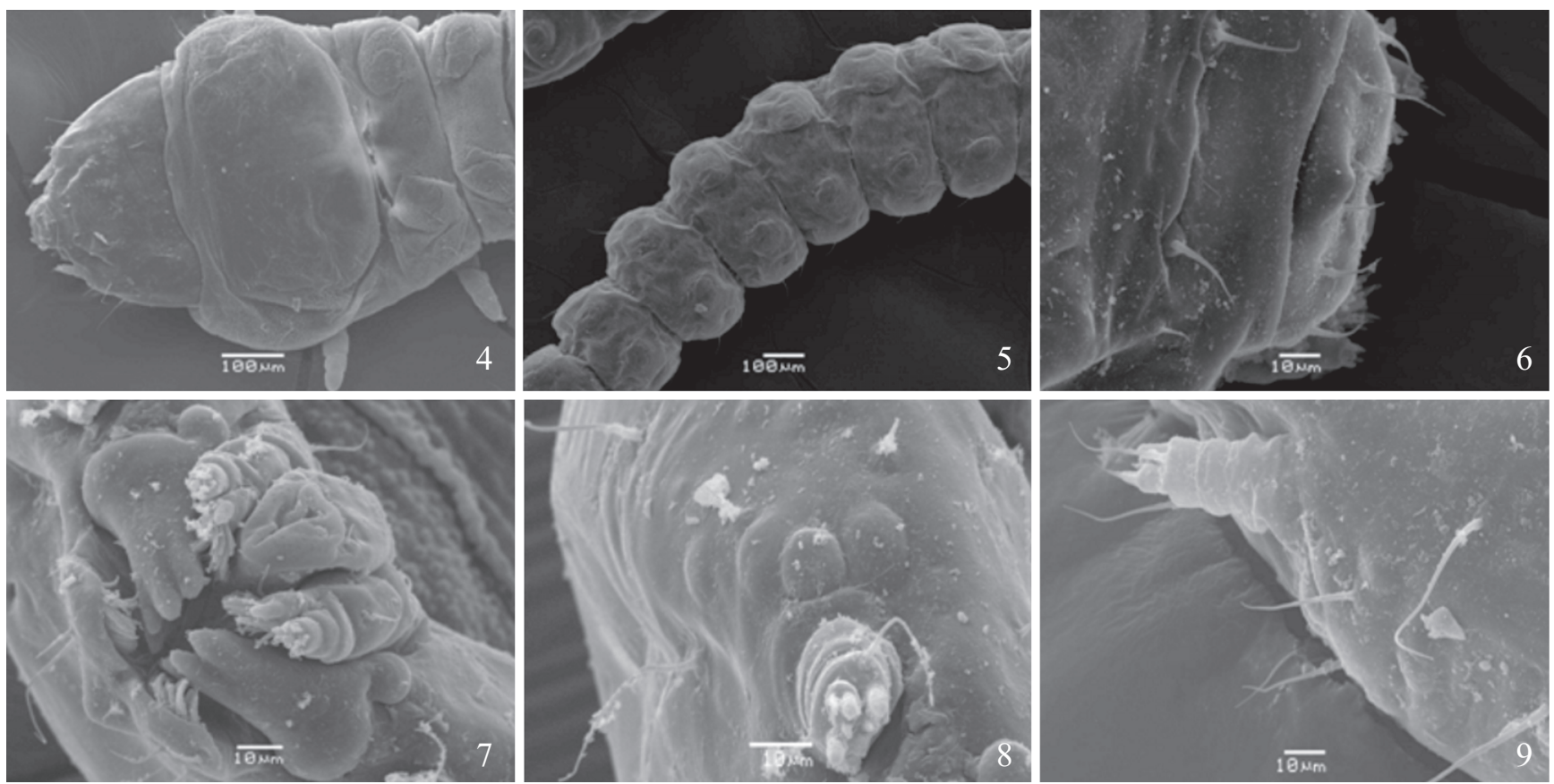

Figs. 4-9. H. pseuderiocrania, larva primer instar. 4, Cabeza y protórax prominente. 5, Segmentos abdominales, vista dorsal. 6, Setas frontales y labro con tres pares de setas. 7, Piezas bucales. 8, Stemmata con 5 stemma. 9, Antena.
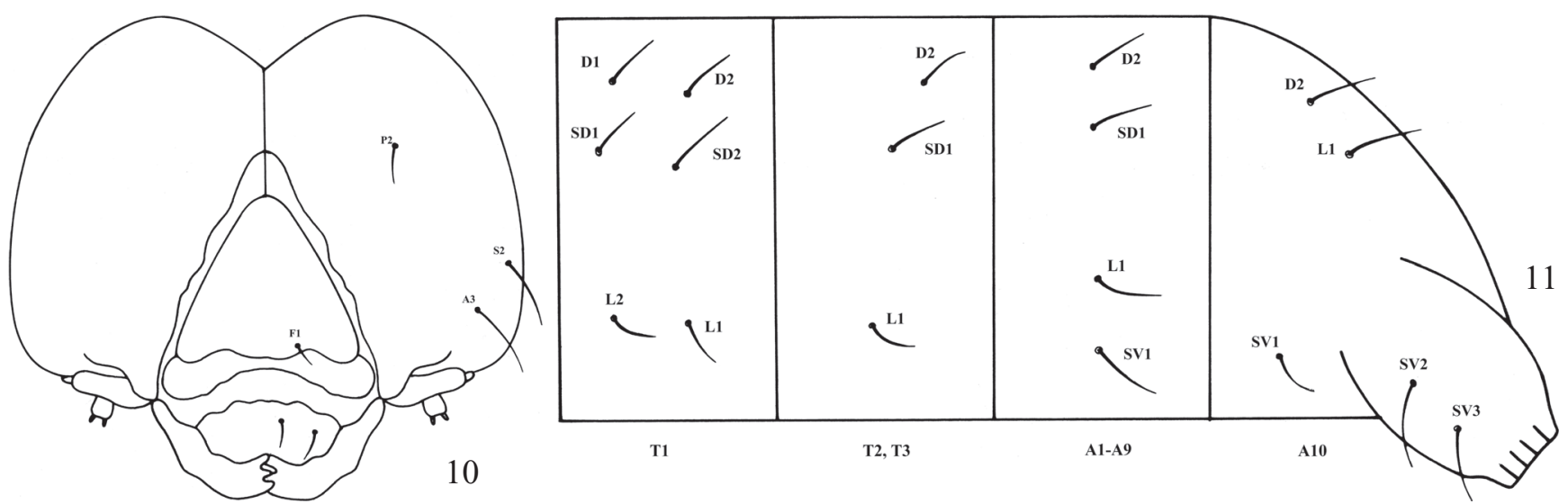

Figs. 10-11. Quetotaxia de la cabeza (10) y del cuerpo (11) de la larva del primer instar. 



Figs. 12-21. H. pseuderiocrania, larva último instar. 12, Cabeza, vista dorsal. 13, Cabeza, vista ventral. 14, Tórax. 15-17, Abdomen. 18, Antena y stemmata con 7 stemma. 19, Setas frontales, clípeo y labro. 20, Quetotaxia de la cabeza. 21, Quetotaxia del cuerpo de la larva del último instar.

SD1, L1, L2, L3, SV1, SV2, V1 y V2 presentes, A8 con D1, D2, SD1, L1, L3, SV1, SV2 y V1 presentes, A9 con D1, D2, L1, L2, L3, SV1, SV2, SV3, V1 y V2 presentes, y A10 con D1, D2, SD1, L1, L3, SV2, SV3 y A10 presentes (Fig. 21).

Material examinado: 13 larvas, Chile: Provincia de Nuble, Localidad de Los Lleuques, 853 m.s.n.m., Nov 2010 (UCCC-MZUC).

Descripción daño. Los minadores de hoja presentan dos tipos de minas: "lineales" y la otra "tipo mancha". En $H$. pseuderiocrania la hembra generalmente ovipone en la superficie abaxial de la hoja, en el centro de las celdillas que se forman entre la nervadura principal y las venas secundarias de la hoja. Desde este punto la larva, una vez eclosionada, forma una corta galería lineal en dirección al borde de la hoja para luego transformarse en una de tipo mancha (Figs. 22 y 23). La cantidad de oviposturas puede variar entre 1 a más de 20 por hoja, lo que coincide con el número de larvas eclosionadas; no obstante, no siempre todas las larvas se desarrollan completamente. En estados avanzados del desarrollo larval, las galerías son del tipo mancha, ocupando en muchos casos, la totalidad 
de la superficie foliar (Figs. 24 y 25). En la temporada $2011-$ 2012, se observó un aumento en el grado de infestación por los minadores en la zona de estudio, lo que no había ocurrido en las dos temporadas anteriores, detectándose además su efecto en plantas jóvenes (Figs. 26 y 27).

Biología y comportamiento. Ovipostura. Kristensen y Nielsen (1983) señalan que las oviposturas se realizan por separado en la superficie abaxial de las hojas tiernas del hospedero, cerca de la nervadura principal y con frecuencia en la línea media entre dos nervaduras secundarias. Además, informan que nunca han observado que las hembras oviponen más de un huevo por hoja, pero que sí oviponen en ramas diferentes. Según los autores, cuando hay más de una ovipostura por hoja (hasta 22 huevos en una sola hoja de $N$. obliqua) se cree que se debe a la oviposición de hembras diferentes. En las muestras se observó la presencia de más de una ovipostura entre las nervaduras secundarias (hasta cuatro) y generalmente se encontraban cercanas a la nervadura principal. La ovipostura provoca en el envés de la hoja un hundimiento del tejido hacia la parte superior de ésta, pudiendo observarse una prominencia por el haz en cada una de ellas (Fig. 28), mientras que por el envés de la hoja se observa una membrana transparente, lisa y plana y puede verse a través de ella el huevo o la larva en desarrollo, en ocasiones de color negro debido a la presencia de fecas. Así, el huevo se encuentra hundido en esta depresión de la hoja (Fig. 29).

En este estudio se monitoreó el comienzo de la oviposición en forma semanal durante el mes de octubre de 2011, encontrándose los primeros huevos en la colecta del 21 de octubre. Sin embargo, para esta fecha ya había desarrollo larval en algunas hojas, lo que indicaría que esta etapa del desarrollo comenzaría unos días antes de esa fecha. En las colectas del 7 y 14 de noviembre, la mayoría de los huevos ya se encontraban eclosionados y las larvas habían construido sus galerías, lo que sugiere que el período de ovipostura es corto, pudiendo tardar sólo un par de semanas.

Ciclo de vida. Con relación al patrón de comportamiento, y de acuerdo a los antecedentes presentados, el ciclo de vida de esta especie se puede resumir de la siguiente forma: se observó que los huevos son puestos a inicios de primavera (mediados de octubre), lo que coincide con la fenología del roble en la formación de los brotes de la nueva temporada. Esta etapa del ciclo de vida es muy corta, encontrándose oviposturas en un período no mayor a un mes, lo que hace suponer que el período de vuelo del imago está restringido a unas pocas semanas. De acuerdo con los registros de larvas, se puede señalar que esta etapa del desarrollo ontogenético tarda aproximadamente 6 meses. Las primeras larvas se colectaron el 21 de octubre y las últimas el 26 de abril del año siguiente. Las trampas dispuestas en el follaje para recoger adultos en las ramillas no lograron obtener ejemplares adultos, lo que permite suponer que las larvas pupan en el suelo y no en las hojas. Además, dado el período de muestreo de este estado del desarrollo, indicaría que la pupación ocurra durante el otoño y que el insecto pase este período en hibernación hasta la llegada de la primavera.

De acuerdo con estos antecedentes, se elaboró un esquema del ciclo biológico de la especie en estudio, en el que se
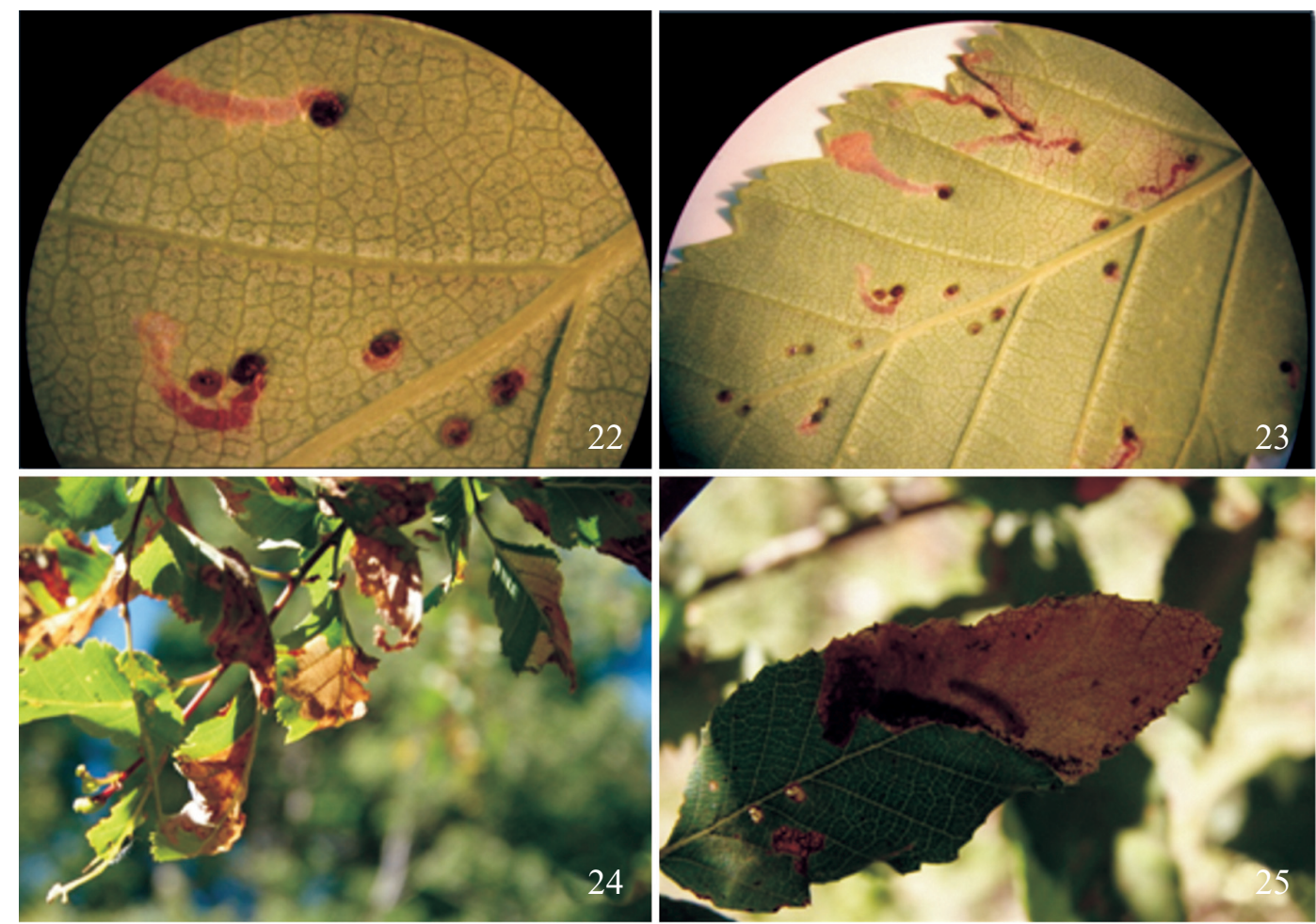

Figs. 22-25. Oviposturas y minas. 22, Minas lineales y oviposturas con larvas del primer instar en su interior (bajo lupa). 23, Oviposturas y cambio de mina lineal a tipo mancha (bajo lupa). 24, Minas avanzadas, tipo mancha. 25, Gran mina tipo mancha con larva y fecas en su interior. 




Figs. 27-29. 26-27, Daños. 26, Árbol juvenil completamente dañado. 27, Daños en ramas de árbol joven. 28-29, Oviposturas. 28, Oviposturas observadas por el haz de la hoja. 29, Oviposturas vistas por la superficie abaxial de la hoja.

indican las fases de desarrollo del insecto y los períodos en que es posible encontrar cada estado de desarrollo (Fig. 30).

Distribución. Se distribuye en el sur de Sudamérica, en bosques templados de Nothofagus de Argentina y Chile. En Argentina, San Martín de Los Andes, Provincia de Neuquén. En Chile, Los Lleuques, Provincia de Ñuble, Región del Biobío.

\begin{tabular}{l}
\hline Estado Ene. Feb. Mar. Abr. May. Jun. Jul. Ago. Sep. Oct. Nov. Dic. \\
\hline Huevo \\
\hline Larva \\
\hline Pupa \\
\hline Adulto
\end{tabular}

Fig. 30. Ciclo de vida de H. pseuderiocrania.

\section{DISCUSIÓN}

En la clasificación taxonómica de lepidópteros mediante caracteres morfológicos es fundamental contar con el estado adulto de las especies en estudio debido a que hay atributos tales como estructura de las piezas bucales, venación alar y genitalia de ambos sexos, que permiten establecer una clasificación a nivel de familia, género y especie. En este estudio no fue posible obtener adultos de la especie en estudio, por lo que se intentó realizar crianza de larvas y pupas, pero ésta no fue exitosa. En el caso de las larvas, por ser minadoras de hoja, básicamente fue debido a que éstas detectaban rápidamente la deshidratación de las hojas, aún en floreros, y huían de sus refugios terminando por morir fuera de sus 
galerías. Para el caso de las pupas que se buscó en la hojarasca y suelo, tampoco hubo un resultado exitoso. Se hace necesario mejorar las técnicas de crianza de larvas y captura de pupas y adultos. Una alternativa de crianza sería establecer un invernadero con setos de roble infestados, permitiendo a los insectos completar su desarrollo larval en las plantas y luego pupar en el suelo, pero bajo condiciones mejor controladas que en su ambiente natural.

El análisis de los resultados moleculares señalan que existe una similitud del $100 \%$ con la especie $H$. pseuderiocrania, por lo tanto, este resultado no es discutible. En relación a los caracteres morfológicos de las larvas de la especie en estudio y, de acuerdo a la descripción hecha por Kristensen \& Nielsen (1983) para H. pseuderiocrania, se puede señalar que tienen gran similitud, exceptuando la estructura de las piezas bucales, específicamente las mandíbulas, en que se observan 4 cúspides (dientes) bien definidas, lo que no coincide con la descripción larval de estos autores, ellos mencionan que las mandíbulas tienen dos cúspides apicales. Kristensen \& Nielsen (1983), en su estudio asumen que sus observaciones biológicas y de los estados inmaduros corresponden y están basadas en $H$. pseuderiocrania, pues es la especie más común $\mathrm{y}$ abundante en su prospección, no asegurando que sus observaciones sean efectivamente de la especie señalada. El ciclo de vida observado en este estudio es bastante similar a la historia de vida relatada por Kristensen \& Nielsen (1983), en relación a la estrecha relación con la fenología del roble.

El patrón de comportamiento en la ovipostura y la construcción de galerías es bastante similar a la descripción de Kristensen \& Nielsen (1983), excepto por pequeñas diferencias observadas en la ovipostura. Este patrón de comportamiento coincide con lo observado en este estudio; sin embargo, difiere en cuanto a que en las muestras se observó la presencia de más de una ovipostura entre las nervaduras secundarias (hasta cuatro). Probablemente, el mayor número de oviposturas entre nervaduras sea producto de la alta tasa de infestación observada en árboles que estaban principalmente al borde de los caminos, en exposición norte y en áreas con cierto grado de alteración por intervención humana (podas en las ramas, raleos, etc.).

La biología de las larvas de H. pseuderiocrania comparados con otras familias de minadores de hoja, se destaca que en $H$. pseuderiocrania la ovipostura ocurre siempre en la superficie abaxial de la hoja; y en relación a la pupación, todo indica que ésta ocurriría en el suelo bajo la hojarasca.

Con relación a la distribución de $H$. pseuderiocrania, y si bien, el género está presente en el sur de Chile y Argentina, hasta ahora esta especie había sido colectada sólo en Argentina, Provincia de Neuquén, al igual que $H$. diffusa y $H$. valvifer, por lo que éste sería el primer registro de $H$. pseuderiocrania para Chile. Sólo $H$. valvifer ha sido colectada en Chile, Provincia de Osorno, Región de Los Lagos, siendo su hospedero Nothofagus pumilio (Kristensen \& Nielsen 1983; Kristensen \& Nielsen 1998).

Cabe destacar la importancia del género Heterobathmia como único representante de una de las tres familias existen- tes del clado Non-Glossata dentro de Lepidoptera, y de excepcional interés filogenético por ser un reducido taxón restringido al sur de Sudamérica, Chile y Argentina, y por encontrarse estrechamente relacionado con los bosques caducifolios de Nothofagus. Esta relación, al igual que la que se produce entre sus especies y los enemigos naturales que las regulan, su probable rol como polinizadores, constituyen interesantes líneas de investigación que pudieran ser consideradas en futuros estudios.

\section{AGRADECIMIENTOS}

Los autores agradecen a la Corporación Nacional Forestal (CONAF), por las facilidades otorgadas para que Rosa Ramos pudiese realizar este estudio. A la empresa Bioforest S.A., por su valiosa colaboración en gestionar la realización del análisis molecular de la especie en estudio, del mismo modo a los investigadores Dr. Bernard Slippers y al Sr. Dawit Degefu, del FABI, Sudáfrica, quienes llevaron a cabo este análisis. Al personal del SEM de la Universidad de Concepción, por su colaboración en la toma de fotografías de ultraestructura. Al Proyecto 210.113.076-1.0 de la Dirección de Investigación de la Universidad de Concepción por el apoyo económico. Finalmente, al Centro de Biotecnología de la Universidad de Concepción por dar las facilidades para el uso del microscopio óptico para fotografiado de larvas.

\section{REFERENCIAS}

Bauerle, P., Rutherford, P. \& Lanfranco, D. 1997. Defoliadores de roble (Nothofagus obliqua), raulí ( $N$. alpina), coigüe ( $N$. dombeyi) y lenga (N. pumilio). Bosque 18: 97-107.

Donoso, C. 1994. Bosques templados de Chile y Argentina. Santiago, Editorial Universitaria, $484 \mathrm{p}$.

Hünefeld, F. \& Kristensen, N.P. 2012. Two new heterobathmiid moth species with distinctive female genita configurations (Lepidoptera: Heterobathmiidae). Zootaxa 3281: 61-68.

Kristensen, N.P. 1984. Studies on the morphology and systematics of primitive Lepidoptera (Insecta). Steenstrupia 10: 141-191.

Kristensen, N.P. 1999. The Non-Glossatan Moths, p. 41-49. In: Kristensen, N.P. (ed.). Lepidoptera, Moths and Butterflies. Volume 1: Evolution, Systematics, and Biogeography. Handbook of Zoology. Band/Volume IV Arthropoda: Insecta, Part 35. Berlin, Walter de Gruyter, 491 p.

Kristensen, N.P. \& Nielsen, E.S. 1979. A new subfamily of micropterigid moths from South America. A contribution to the morphology and phylogeny of the Micropterigidae, with a generic catalogue of the family (Lepidoptera: Zeugloptera). Steenstrupia 5: 69-147.

Kristensen, N.P. \& Nielsen, E.S. 1983. The Heterobathmia life history elucidated: Immature stages contradict assignment to suborder Zeugloptera (Insecta, Lepidoptera). Zeitschrift für Zoologische Systematik und Evolutionsforschung 21: 101-124.

Kristensen, N.P. \& Nielsen, E.S. 1998. Heterobathmia valvifer n. sp.: A moth with large apparent 'ovipositor valves' (Lepidoptera: Heterobathmiidae). Steenstrupia 24: 141-156.

Nielsen, E.S. 1985. Primitive (non-ditrysian) Lepidoptera of the Andes: diversity, distribution, biology and phylogenetic relationships. Journal of Research on Lepidoptera, Suppl. 1: 1-16.

Received 16 October 2012; accepted 25 January 2013

Associate Editor: Claudio J. B. Carvalho 